\title{
Using Component Test Data to Assist \\ in Establishing Code Criteria to Achieve the Desired \\ Seismic Capacity Margin for Piping
}

\author{
Robert P. Kennedy
}

\section{Introduction}

In order to preclude piping from becoming a significant contributor to the seismic risk of core damage at a nuclear power plant, Refs. 1 and 2 recommend that the seismic capacity margin $\mathrm{R}_{\mathrm{CP}_{1 \%}}$ corresponding to a $1 \%$ probability of failure should be about 2.0. It is most convenient to consider the Seismic Capacity Margin $\mathrm{R}_{\mathrm{CP}}$ to be composed of the product of three parts, i.e.:

$$
\mathrm{R}_{\mathrm{CP}}=\mathrm{F}_{\mathrm{S}} \mathrm{F}_{\mathrm{NL}} \mathrm{F}_{\mathrm{Red}}
$$

where $F_{S}$ is a strength factor, $F_{\mathrm{NL}}$ is the additional factor due to nonlinear dynamic behavior, and $F_{R e d}$ is a redundancy factor associated with the load redistribution that will occur when a region is overstressed in an actual piping system.

The strength factor $F_{S}$ is given by:

$$
\mathrm{F}_{\mathrm{S}}=\frac{\mathrm{M}_{\mathrm{UD}}}{\mathrm{M}_{\mathrm{CODE}}}
$$

where $\mathrm{M}_{\mathrm{UD}}$ is the ultimate moment achieved in any component under dynamic cyclic loading prior to failure and $\mathrm{M}_{\mathrm{CODE}}$ is the ASME code moment capacity for seismic loadings. This strength margin can be estimated with minimum controversy from the available component test data since $\mathrm{M}_{\mathrm{UD}}$ can be estimated with little uncertainty for each tested component. In all of the component tests described in Refs. 3 and 4, the nonlinear hysteretic behavior of the component prior to failure was similar to that shown in Figure 1. A moment capacity close to the ultimate moment capacity $\mathrm{M}_{\mathrm{UD}}$ was reached at a relatively small rotation (typically in the range of 0.02 or 0.04 radians). However, failure did not occur until a substantially greater rotation (typically 0.06 to 0.1 radians) was exceeded. This behavior occurred irrespective of whether the ultimate failure was a low cycle ratchet-fatigue failure or was excessive deformation (collapse or deflection based failure). The seismic margins shown by the analyses presented in Ref. 5 are highly variable and are sensitive to the ratio $R_{W}$ between the input and component frequency, the breadth of the input motion frequency content, and the postulated failure mode (fatigue versus displacement). For example, see Figures 2 and 3. 
However, in each analysis case the maximum moment reached prior to failure was approximately $\mathrm{M}_{\mathrm{UD}}$. Therefore, $\mathrm{M}_{\mathrm{UD}}$ remains a stable description of the component strength irrespective of the input time history, the component frequency, and the failure mode (low cycle fatigue or deformation). As such, $F_{S}$ is a stable strength factor for each tested component.

The nonlinear factor $F_{\mathrm{NL}}$ is highly sensitive to both the ratio $R_{\mathrm{W}}$ of the central frequency of the input motion to the component natural frequency, and the breadth of the frequency content of the input motion as well as the assumed failure mode (low cycle fatigue versus deformation): Therefore, it will be very difficult and probably impossible to reliably estimate $\mathrm{F}_{\mathrm{NL}}$ for an actual piping system without performing a nonlinear dynamic analyses coupled with a nonlinear acceptable strain or inelastic rotation criterion. However, the nonlinear component analyses presented in Ref. 5 do enable some reasonably conservative estimates of $\mathrm{F}_{\mathrm{NL}}$ to be made as will be discussed in Section 4 .

The redundancy factor $F_{\text {Red }}$ is unity in the component tests because no redundancy benefit exists in these tests. For actual piping systems $F_{\text {Red }}$ will vary somewhat from system to system. However, some reasonably conservative generic estimates of $F_{\text {Red }}$ can be made as will be discussed in Section 5.

From Eqn. (1), the $1 \%$ probability of failure capacity margin $\mathrm{R}_{\mathrm{CP}_{1 \%}}$ can be estimated from:

$$
\mathrm{R}_{\mathrm{CP}_{1 \%}}=\mathrm{F}_{\mathrm{S}_{1 \%}}\left(\mathrm{~F}_{\mathrm{NL}} \mathrm{F}_{\mathrm{Red}}\right)_{\mathrm{CONS}}
$$

where $\mathrm{F}_{\mathrm{S}_{1 \%}}$ is the $1 \%$ non-exceedance probability (NEP) strength factor which can be directly estimated from the component test data, and $\left(\mathrm{F}_{\mathrm{NL}} \mathrm{F}_{\mathrm{Red}}\right)_{\text {cons. }}$ represents a reasonably conservative generic estimate of the product of $F_{\mathrm{NL}}$ and $\mathrm{F}_{\mathrm{Red}}$. Based on the considerations presented in Ref. 6 , the product $\left(\mathrm{F}_{\mathrm{NL}} \mathrm{F}_{\mathrm{Red}}\right)_{\mathrm{CONS}}$ should be established sufficiently conservatively that there is less than about a $16 \%$ probability that the actual product would be less for any specific piping system and seismic input. It is recommended that a conservative generic estimate be made by consensus of a committee using the Ref. 5 results as guidance. Some further guidance is given in Section 5.

Once a consensus estimate of $\left(\mathrm{F}_{\mathrm{NL}} \mathrm{F}_{\mathrm{Red}}\right)_{\mathrm{CONS}}$ is established, then the required strength factor $\mathrm{F}_{\mathrm{S}_{1 \%}}$ needed to achieve the goal of $\mathrm{R}_{\mathrm{CP}_{1 \%}}=2.0$ is given by: 


$$
\mathrm{F}_{\mathrm{S}_{1 \%}}=\frac{2.0}{\left(\mathrm{~F}_{\mathrm{NL}} \mathrm{F}_{\mathrm{Red}}\right)_{\mathrm{CONS}}}
$$

\begin{tabular}{|c|c|}
\hline$\left(\mathrm{F}_{\mathrm{NL}} \mathrm{F}_{\mathrm{Red}}\right)_{\text {CONS }}$ & $\mathrm{F}_{\mathrm{S}_{1 \%}}$ \\
\hline 1.0 & 2.0 \\
1.33 & 1.5 \\
1.5 & 1.33 \\
1.8 & 1.1 \\
2.0 & 1.0 \\
\hline
\end{tabular}

In my opinion, a $\left(\mathrm{F}_{\mathrm{NL}} \mathrm{F}_{\mathrm{Red}}\right)_{\mathrm{CONS}}$. of at least 1.33 can be easily justified. Therefore, in the next section, an equation for the code moment capacity $\mathrm{M}_{\mathrm{CODE}}$ which is aimed at achieving a $1 \%$ NEP strength factor $\mathrm{F}_{\mathrm{S}_{1 \%}}$ of about 1.5 is presented. It is then demonstrated in Section 3 that this proposed equation for $\mathrm{M}_{\mathrm{CODE}}$ does achieve $\mathrm{F}_{\mathrm{S}_{1 \%}}$ of about 1.5 for fittings (Elbows, Bends, and Tees) and the weld region attaching fittings to straight pipe based on the component test data presented in Refs. 3 and 4.

A major advantage of this approach is that seismic margin against failure occurs irrespective of whether the ultimate failure is a low cycle ratchet-fatigue failure or is excessive deformation (collapse or deflection based failure). Another major advantage is that seismic response is limited to basically the linear range of response. Thus, linear piping analysis is applicable. A major disadvantage is that the actual $\left(\mathrm{F}_{\mathrm{NL}} \mathrm{F}_{\text {Red }}\right)$ corresponding to failure for a piping system subjected to a specified seismic input is most likely to significantly exceed the generic conservative $\left(\mathrm{F}_{\mathrm{NL}} \mathrm{F}_{\mathrm{Red}}\right)$ value at 1.33 . However, this additional seismic capacity margin cannot be assessed without performing nonlinear seismic analysis.

\section{Proposed Equation for Code Seismic Moment Capacity $\mathrm{M}_{\mathrm{CODE}}$}

For reversing dynamic loads similar to seismic it is proposed that the code moment capacity $\mathrm{M}_{\mathrm{CODE}}$ resulting from weight stress, dynamic inertia effects, and other mechanical loads be limited to:

$$
\begin{aligned}
& \mathrm{M}_{\mathrm{CODE}}=\left|\mathrm{S}_{\mathrm{A}}-\frac{\mathrm{B}_{1}^{\prime} \mathrm{PD}_{0}}{2 \mathrm{t}}\right| \frac{\mathrm{Z}_{\mathrm{N}}}{\mathrm{B}_{2}^{\prime}} \\
& \mathrm{S}_{\mathrm{A}}=3.0 \mathrm{~S}_{\mathrm{M}}
\end{aligned}
$$

where: $\mathrm{S}_{\mathrm{A}}=$ reversing dynamic load allowable stress

$\mathrm{S}_{\mathrm{M}}=$ ASME Code material allowable stress

$\mathrm{P}=$ Pressure coincident with dynamic loading 


$$
\begin{aligned}
\mathrm{D}_{0} & =\text { Outside pipe diameter } \\
\mathrm{t} & =\text { Pipe wall thickness } \\
\mathrm{Z}_{\mathrm{N}} & =\text { Nominal Section Modulus } \\
\mathrm{B}_{1}^{\prime} \mathrm{B}_{2}^{\prime} & =\text { Dynamic Stress Indices }
\end{aligned}
$$

Equation (5) is identical to the pre-1994 edition of the ASME Boiler and Pressure Vessel Code, Section III (ASME Code) except for the substitution of $\mathrm{B}_{1}^{\prime}$ and $\mathrm{B}_{2}^{\prime}$ for the code $B_{1}$ and $B_{2}$ values. It is proposed that $B_{1}^{\prime}$ and $B_{2}^{\prime}$ be defined as follows:

Elbows, Bends and Tees

$$
\begin{aligned}
& \mathrm{B}_{2}^{\prime}=(2 / 3) \mathrm{B}_{2} \geq 1.0 \\
& \mathrm{~B}_{1}^{\prime}=\left\{\begin{array}{l}
0 \quad \text { Elbows and Bends } \\
0.5 \text { Tees }
\end{array}\right.
\end{aligned}
$$

Weld Region Connecting Fittings to Pipe or Other Location of Abrupt Stiffness Change

$$
\begin{aligned}
& \mathrm{B}_{2}^{\prime}=(4 / 3) \\
& \mathrm{B}_{1}^{\prime}=0.5
\end{aligned}
$$

Other Fittings Where Data To Justify A Reduction Is Unavailable

$$
\begin{aligned}
& \mathrm{B}_{2}^{\prime}=\mathrm{B}_{2} \\
& \mathrm{~B}_{1}^{\prime}=\mathrm{B}_{1}
\end{aligned}
$$

Straight Pipe

$$
\begin{aligned}
& \mathrm{B}_{2}^{\prime}=1.0 \\
& \mathrm{~B}_{1}^{\prime}=0.5
\end{aligned}
$$

where $B_{1}$ and $B_{2}$ are the stress indices based on the 1994 ASME Code.

Equation ( $5 \mathrm{a}$ ) reduces the current code $\mathrm{B}_{2}$ values by an amount equivalent to raising the reversing dynamic load allowable stress to $4.5 \mathrm{~S}_{\mathrm{M}}$ with current code $B_{2}$ values for Elbows, Bends, and Tees. It is shown in the next section that the component test data reported in Refs 3 and 4 justifies this relaxation of the pre1994 code moment capacity for these components in order to achieve a $\mathrm{F}_{\mathrm{S}_{1 \%}}$ of about 1.5. Conversely, it could also have been shown that the 1994 Addendum 
change to the ASME Code to a dynamic stress allowable of $4.5 \mathrm{~S}_{\mathrm{M}}$ achieves a $\mathrm{F}_{\mathrm{S}_{1 \%}}$ of about 1.5 for these components.

A number of the component failures reported in Refs. 3 and 4 occurred near the weld joining the fitting to the straight pipe as opposed to the body of the fitting. $\mathrm{B}_{1}^{\prime}$ and $\mathrm{B}_{2}^{\prime}$ values are defined by Eqn. (5b) for this location which is subject to some strain concentration as a result of the abrupt stiffness change between the straight pipe and the fitting. With these $B_{1}^{\prime}$ and $B_{2}^{\prime}$ values, it is shown in the next section that the resultant strength factor $F_{S}$ for failures near this weld location are consistent with the $F_{S}$ failures in the body of Elbows, Bends, and Tees using Eqn. (5a) and that a $\mathrm{F}_{\mathrm{S}_{1 \%}}$ of about 1.5 is also achieved for these near weld location failures.

Eqns. (5c) and (5d) are identical with the pre-1994 ASME Code values for defining $\mathbf{M}_{\mathrm{CODE}}$ because no data was reviewed for these cases. Therefore, no change was justified at this time for these cases.

\section{Component Test Data Strength Factor $F_{S}$ \\ 3.1 Presentation of Test Data Considered}

As noted previously, for any tested component, the strength factor $F_{S}$ is given by Eqn. (2). With an assumed lognormal distribution, the seismic strength factor $\mathrm{F}_{\mathrm{S}_{1 \%}}$ corresponding to a $1 \%$ probability of failure can be estimated by:

$$
F_{S_{1 \%}}=F_{S_{50 \%}} e^{-2.326 \beta_{S}}
$$

where $\mathrm{F}_{\mathrm{S}_{50 \%}}$ is the median seismic strength factor from all of the test data, and $\beta_{\mathrm{S}}$ is the logarithmic standard deviation of the test data.

Ref. 3 presents and discusses EPRI (ANCO) dynamic component test data. Table 1 summarizes these component tests. The component test number is shown in the first column. The component type is also defined in this column using the following abbreviations: $\mathrm{EL}=$ Elbow, $\mathrm{Tee}=\mathrm{Tee}, \mathrm{Red}=$ Reducer, Pipe $=$ Pipe, $\mathrm{LR}=$ long radius, $\mathrm{SR}=$ short radius, $10=\mathrm{Scd} .10$, and $40=\mathrm{Scd} .40$. The material is defined by $\mathrm{CS}=$ carbon steel, $\mathrm{SS}=$ stainless steel. The parameter values $\left(\mathrm{Z}_{\mathrm{N}}\right.$, $\frac{\mathrm{PD}_{\mathrm{o}}}{2 \mathrm{t}}, \mathrm{B}_{1}$, and $\mathrm{B}_{2}$ ) shown are those recommended in Table 2 of Ref. 3. The ultimate moment capacity $M_{\mathrm{UD}}$ shown is also that defined in Table 2 of Ref. 3. When failure occurred in the body of the fitting, the $B_{1}$ and $B_{2}$ values shown are those computed using ASME Code equations. When the failure was near a weld region connecting a fitting to a pipe, $\mathrm{B}_{1}=0.5$, and $\mathrm{B}_{2}=1.0$ are shown. Even 
though Component \#34 is defined as a Scd. 40 straight pipe, the failure was near a weld to a Scd. 160 pipe segment so that it also was near a weld at an abrupt stiffness change. Table 1 also presents the $\mathrm{M}_{\mathrm{CODE}}$ computed from the proposed code capacity Eqn. (5) combined with Eqn. (5a) for the 13 tested Elbows and the 2 tested Tees where failure occurred in the body of the Tee, and combined with Eqn. (5b) for the other 10 Non-Elbow tests where the failure occurred near a weld at a stiffness discontinuity. Lastly, Table 1 presents the strength factor $F_{S}$ computed from Eqn. (2)

Ref. 4 presents Japanese component test data. The Japanese performed both dynamic shake table tests and deformation controlled cyclic static tests. Table 2 presents the Japanese dynamic component test data. The Japanese cyclic static component test data is shown in Table 3. Except for $\mathrm{B}_{1}$ for Bends, the parameter values and ultimate moment capacities $M_{U D}$ shown in Tables 2 and 3 are those recommended in Ref. 4 . For Bends $B_{1}=0$ was used even though Ref. 4 showed $\mathrm{B}_{1}=0.5$ because the resulting $\mathrm{F}_{\mathrm{S}_{1 \%}}$ are much more consistent across all of the Bends when $B_{1}=0$ is used. In other words, the data shows that ultimate moment capacities are not reduced by internal pressure for Bends. Again, when failure occurred in the body of the fitting, the $\mathrm{B}_{1}$ and $\mathrm{B}_{2}$ values shown are those computed using ASME Code equations. When the failure was near a weld connecting a fitting to a pipe, $B_{1}=0.5$ and $B_{2}=1.0$ are shown. The three pipe components shown in Tables 2 and 3 all failed near a weld at an abrupt stiffness discontinuity and are not representative of pure straight pipe or welds between similar stiffness pipe segments. Tables 2 and 3 also present the $M_{\mathrm{CODE}}$ computed from Eqn. (5) combined with either Eqn. (5a) or Eqn. (5b), whichever was appropriate, as well as the resulting strength factor $F_{S}$.

\subsection{Computation of Statistical Parameters For Strength Factor F}

EPRI Elbow Component \#37 has been left out of all computations of the statistical parameters for the strength factor $F_{S}$ discussed in this section because its $F_{S}$ is clearly not of the same distribution as the other 12 EPRI Elbow Components shown in Table 1. The median $\mathrm{F}_{\mathrm{S}}$ for the other 12 Elbow components is 2.02 with $\beta_{S}=0.13$. Thus the $F_{S}$ of Elbow Component \#37 lies 5.5 standard deviations below the median of the other 12 Elbow components. If all of the Elbow component $F_{S}$ were part of the same distribution, the likelihood that one out of 13 tests would lie at least 5.5 standard deviations below the median is infinitesimally small. Elbow Component \#37 is clearly an outlier from the other tested Elbow components and must be separately considered.

An open question is whether the EPRI dynamic tests (Table 1), Japanese Dynamic tests (Table 2), and Japanese Cyclic Static tests (Table 3) can all be 
combined into a single data base. Statistical distribution information on the strength factor $F_{S}$ obtained for these three sets of tests are shown in Table 4. This statistical data (median $\mathrm{F}_{\mathrm{S}_{50 \%}}$, logarithmic standard deviation $\beta_{\mathrm{S}}$, and $1 \% \mathrm{NEP}$ strength factor $\mathrm{F}_{\mathrm{S}_{1 \%}}$ ) is computed on the assumption that all the data is lognormally distributed. This assumption will subsequently be verified.

A statistical test of the hypothesis that the strength factors $F_{S}$ for the Japanese dynamic and cyclic static tests are both part of the same distribution is easily accepted at the $5 \%$ level of significance. Therefore, the Japanese dynamic and cyclic static test data can be combined to produce a total Japanese data set of 26 tests.

The observation that dynamic and cyclic static ultimate moment capacities are nearly equal is very interesting for future test consideration. It indicates that $\mathrm{M}_{\mathrm{UD}}$ can be reasonably estimated from deformation controlled cyclic static tests. Deformation controlled cyclic static tests are much easier to perform, instrument, and interpret the data than are dynamic shake table tests.

It is not clear whether the EPRI and Japanese test data $F_{S}$ values are part of the same distribution. At the 5\% level of significance, the hypothesis that they are part of the same distribution is rejected. However, this hypothesis is accepted at the $1 \%$ level of significance. Whether the hypothesis is accepted or not accepted :

$$
\mathrm{F}_{\mathrm{S}_{1 \%}} \approx 1.5
$$

for both EPRI and Japanese component test data. Therefore, from a practical standpoint, it is preferable to accept the hypothesis because this acceptance produces a combined data base of 50 data points while having very little impact on the computed $1 \%$ NEP strength factor $\mathrm{F}_{\mathrm{S}_{1 \%}}$.

Secondly, it is necessary to demonstrate that using Eqn. (5a) to define $\mathrm{B}_{1}^{\prime}$, and $\mathrm{B}_{2}^{\prime}$ for failures in the body of Elbows, Bends and Tees while using Eqn. (5b) to define $\mathrm{B}_{1}^{\prime}$ and $\mathrm{B}_{2}^{\prime}$ for failures near weld regions with abrupt stiffness changes enables these two data sets to be combined. Table 5 compares the statistical distribution information on $\mathrm{F}_{\mathrm{S}}$ obtained from these two data sets. Again, whether the two sets of data are combined or not combined has very little impact on the computed $1 \%$ NEP strength factor $\mathrm{F}_{\mathrm{S}_{1 \%}}$. 
A third check is made to determine whether the strength factor statistical distribution properties are significantly different for stainless steel and carbon steel components when $S_{M}$ is used to define $M_{C O D E}$ in Eqn. (5). Table 6 compares the statistical distribution information on $\mathrm{F}_{S}$ obtained for carbon steel versus stainless steel components. Again, whether the two sets of data are combined or not has very little impact on the computed $1 \%$ NEP strength factor $\mathrm{F}_{\mathrm{S}_{1} \%}$.

Lastly, it remains to be shown whether the data is reasonably approximated as being lognormally distributed. This is best shown by ordering the data from low to high and plotting the natural logarithm of the seismic strength factor $F_{S}$ versus the non-exceedance probability $\mathrm{P}_{\mathrm{NE}}$ on cumulative normal probability paper, where $\mathrm{P}_{\mathrm{NE}}$ is defined by:

$$
\mathrm{P}_{\mathrm{NE}}=\frac{\mathrm{n}}{\mathrm{N}+1}
$$

in which $\mathrm{n}$ is the ordered data number, and $\mathrm{N}$ is the total number of data. Since $\mathrm{N}=50$, the first ordered data is plotted at the $1.96 \%$ probability point, the second at $3.92 \%$, etc., with the last at $98.04 \%$. If the data is lognormally distributed, it will appear as a straight line on this plot. Figure 4 shows such a plot using the combined seismic strength factor data from Tables 1 through 3 . This figure shows that the data can be reasonably approximated by a lognormal distribution at least between the $2 \%$ and $98 \%$ probability of failure range. The open question remains as to whether this lognormal distribution can be extrapolated down to the $1 \%$ probability of failure.

The problem is that the lognormal distribution extends down to a zero probability of failure at zero capacity. However, real capacity data achieves essentially a zero probability of failure at some lower bound capacity level significantly greater than zero. Therefore, most real data can generally be better represented by a truncated lognormal distribution in which the parameter $\left(\mathrm{F}_{\mathrm{S}}-\mathrm{F}_{\mathrm{S}_{\text {min }}}\right)$ is assumed to be lognormally distributed. The problem being how to establish the truncation level $\mathrm{F}_{\mathrm{S}_{\min }}$ when only a limited amount of data is available. The shape of the lower tail of the data plotted on Figure 4 does not indicate that any truncation level exists. In order to realistically estimate $\mathrm{F}_{\mathrm{S}_{\min }}$ would require about 100 to 200 pieces of test data which is impractical. It is recommended that no truncation be assumed. 


\subsection{Conclusions Concerning 1\% NEP Strength Factor $\mathrm{F}_{\mathrm{S}_{1 \%}}$}

It is concluded that the strength factor $\mathrm{F}_{\mathrm{S}}$ is lognormally distributed and that the $1 \%$ NRP strength factor $\mathrm{F}_{\mathrm{S}_{1} \%}$ is reasonably defined by Eqn. (7) for all of the data presented in Tables 1 through 3 except for EPRI Elbow Component \#37. This component is further discussed in the next subsection.

\subsection{EPRI Elbow Component \# 37}

For EPRI Elbow Component \#37, the Code Moment Capacity Eqns. (5) and (5a)provides a strength factor $F_{S}$ of only 1.0. For the 50 other tested components, this same Code Moment Capacity Eqn. (5) coupled with either Eqn. (5a) or Eqn. (5b), as appropriate, provides a median strength factor $\mathrm{F}_{\mathrm{S}_{50 \%}}$ of about 2.2 and a $1 \%$ NEP strength factor of about 1.5. As a result, it is necessary to understand the cause of Elbow Component \#37 having an abnormally low ultimate dynamic moment capacity $\mathrm{M}_{\mathrm{UD}}$.

For all 33 other fitting tests where failure was in the fitting body, the ultimate dynamic moment capacity $\mathrm{M}_{\mathrm{UD}}$ significantly exceeded the expected ultimate static moment capacity $\mathrm{M}_{\mathrm{US}}$. This increase is most likely due to cyclic strengthening as a result of prior nonlinear cycles. However, Elbow Component $\# 37$ does not show a similar increase. For Elbow Component \#37, $\mathrm{M}_{\mathrm{UD}} \approx \mathrm{M}_{\mathrm{US}}$.

In many respects the dynamic testing of Elbow Component \#37 was near the extreme range of tests conducted. Thus, there are a number of postulated reasons for the apparent lack of dynamic moment capacity increase for this component. The most likely causes are:

1. Elbow Component \#37 had a low natural frequency $f_{N}$ of $1.44 \mathrm{~Hz}$ and a low central frequency $f_{I}$ for the input motion of $1.40 \mathrm{~Hz}$. The only other component with similarly low frequencies was Elbow Component \#30. For all other tested components the natural and input central frequencies were at least 2.5 times greater.

2. Both Elbow Components \#30 and 37 had ratios of Weight Moment $\mathrm{M}_{\mathrm{W}}$ to Code Moment $\mathrm{M}_{\mathrm{CODE}}$ of 0.12 . The only other Elbow with a significant ratio of Weight Moment to Code Moment was Component \#35 for which this ratio was 0.086 . However, Component \#35 was a Sch. 40 Elbow, whereas Components \#30 and 37 were Sch. 10 Elbows. Furthermore, these Weight Moments were in the Elbow closing direction. 
3. Elbow Components \#37 and 8 were the only Elbows for which $\frac{P D}{2 t}$ was less than about $10.0 \mathrm{ksi}$. These Elbows had zero pressure. In fact this zero pressure was the only difference between Elbow Component \#37 and Elbow Component \#30. Elbow Component \#8 differed from Elbow Component \#37 in that Elbow Component \#8 was a Sch. 40 Elbow, had negligible weight moment, and approximately 5 times higher natural and input central frequencies.

4. Elbow Components \#3, 30, 31, and 37 were the only Sch. 10 Elbow for which $\mathrm{D}_{0} / \mathrm{t} \approx 50$. All of the other Elbows were Sch. 40 for which $D_{0} / t \approx 24$. Elbow Component $\# 30$ had a slightly below average strength factor of 1.83. However, Elbow Components \#3 and \#31 had above average strength factors so that $D_{0} / t$ does not seem to be the primary cause of the low $\mathrm{M}_{\mathrm{UD}}$ for Elbow Component \#37.

5. Because of a longer lever arm above Elbows \#30 and \#37 to the added weight, these Elbows had a larger P- $\Delta$ negative stiffness $k_{P-\Delta}$ of -97 kips-inch per radian than any other elbows. Also the Schedule 10 Elbows have a lower initial restoring moment stiffness estimated to be about 2100 kips-inch per radian. The ratio of $P-\Delta$ stiffness to initial stiffness was about -0.05 . Studies presented in Ref. 5 show that negative ratios greater than about -0.02 greatly increase the tendency for one-way ratcheting to continue to collapse once oneway ratcheting begins.

Elbow Components \#30 and 37 were essentially identical and were subjected to essentially the same input. However, $\frac{P D}{2 t}=0$ for Component $\# 37$ and $\frac{\mathrm{PD}}{2 \mathrm{t}}=9.9 \mathrm{ksi}$ for Component \#30. It is informative to compare the nonlinear moment-rotation hysteretic loops for Component \#37 (see Figure 5) versus Component \#30 (see Figure 6). For both components the weight moment stress:

$$
\frac{\mathrm{B}_{2} \mathrm{M}_{\mathrm{W}}}{\mathrm{Z}_{\mathrm{N}}} \approx 0.5 \mathrm{~S}_{\mathrm{M}}
$$

This weight moment stress has the tendency to ratchet the elbow closed when subjected to a cyclic moment of approximately $\mathrm{M}_{\mathrm{US}} \approx 4.5 \mathrm{~S}_{\mathrm{M}}\left(\mathrm{Z}_{\mathrm{N}} / \mathrm{B}_{2}\right)$ as shown in Figure 5. Because of this one-way ratcheting, full reverse nonlinear opening cycles never developed. Therefore, cyclic strengthening did not occur and: 
Component \#37

$$
\mathrm{M}_{\mathrm{UD}} \approx \mathrm{M}_{\mathrm{US}} \approx 4.5 \mathrm{~S}_{\mathrm{M}}\left(\frac{\mathrm{Z}_{\mathrm{N}}}{\mathrm{B}_{2}}\right)
$$

However, the pressure stress $\frac{\mathrm{PD}}{2 \mathrm{t}} \approx 0.5 \mathrm{~S}_{\mathrm{M}}$ on Component $\# 30$ has the tendency to provide an opening effect on the Elbow which resists the tendency of the weight moment stress to ratchet the elbow closed. Thus, the full opening and closing hysteretic loop, shown in Figure 6 develop in Component \#30 resulting in cyclic strengthening. Thus, for Component $\# 30 \mathrm{M}_{\mathrm{UD}}$ is significantly greater than $\mathrm{M}_{\mathrm{US}}$ and:

$$
\frac{\text { Component \#30 }}{\mathrm{M}_{\mathrm{UD}} \approx 8.2 \mathrm{~S}_{\mathrm{M}}\left(\frac{Z_{\mathrm{N}}}{\mathrm{B}_{2}}\right)}
$$

It is likely that the unfavorable combination of no internal pressure, high weight moment stress in the closing direction, and a high negative ratio of $\mathrm{P}-\Delta$ stiffness to initial stiffness was the cause of the low $M_{U D}$ and lesser performance for Elbow Component \#37. This unfavorable combination is considered to be highly unlikely in an actual piping system. Even so, the low capacity of Elbow Component \#37 remains the topic of further study and discussion.

\section{Nonlinear Dynamic Behavior Factor For Component Tests}

Ref. 5 presents a number of parametric study results which demonstrate how a Margin Factor $\left(M_{r} / B_{2}\right)$ vary as a function of (1) the frequency ratio $R_{W}$ of the input motion central frequency $f_{I}$ to the component natural frequency $f_{n},(2)$ the breadth of the frequency content of the input motion, (3) model parameters, and (4) the assumed failure mode (for example, low cycle fatigue versus excessive nonlinear deformation failures). Figures 2 and 3 are examples of the Margin Factor information presented in Ref. 5. The PFDR input motion used in Ref. 5 is an example of narrow frequency input motion representative of floor motion at a high elevation of moderately low damped stiff structure. The Reg. 1.60 input motion used in Ref. 5 is an example of a very broad frequency ground motion Therefore, these two motions tend to represent examples of the extremes on the breadth of frequency content in the input motion to which a piping component might be subjected.

The Margin Factor $M_{r}$ used in Ref. 5 and the Seismic Capacity Margin $R_{C P}$ used herein and in Ref. 1 and 2 are synonymous for component tests where the 
redundancy factor $F_{R e d}$ is 1.0 . However, the $\mathrm{M}_{\text {CODE }}$ used in Ref. 5 differs from that defined by Eqn. (5). As a result, the component nonlinear dynamic factor $F_{\mathrm{NLC}}$ for any situation studied in Ref. 5 is:

$$
\mathrm{F}_{\mathrm{NLC}}=\frac{\mathrm{F}_{\mathrm{C}} \mathrm{B}_{2}}{\mathrm{~F}_{\mathrm{S}}}\left(\frac{\mathrm{M}_{\mathrm{r}}}{\mathrm{B}_{2}}\right)
$$

where $B_{2}$ and $F_{S}$ are from Table 1 , and $F_{C}$ is a conversion factor:

$$
\begin{array}{ll}
\text { Elbows, Bends, and Tees: } & \mathrm{F}_{\mathrm{C}}=1.0 \text { to } 1.07 \\
\text { Weld Region Connecting Fittings: } & \mathrm{F}_{\mathrm{C}}=2.0 \text { to } 2.14
\end{array}
$$

The parametric studies presented in Ref. 5 are primarily for Components \#14 and 40 for which:

\begin{tabular}{|c|c|}
\hline Component & $\mathrm{F}_{\mathrm{C}} \mathrm{B}_{2} / \mathrm{F}_{\mathrm{S}}$ \\
\hline 14 & 1.10 \\
40 & 0.92 \\
\hline
\end{tabular}

Thus, for these two components:

$$
\mathrm{F}_{\mathrm{NLC}} \approx\left(\frac{\mathrm{M}_{\mathrm{r}}}{\mathrm{B}_{2}}\right)
$$

so that all of the figures in Ref. 5 of $\left(\mathrm{M}_{\mathrm{r}} / \mathrm{B}_{2}\right)$ versus $\mathrm{R}_{\mathrm{W}}$ for these components are approximately plots of $F_{\mathrm{NLC}}$. Therefore, Ref. 5 provides an excellent basis for understanding $\mathrm{F}_{\mathrm{NLC}}$.

A study of the plots of $\left(\mathrm{M}_{\mathrm{r}} / \mathrm{B}_{2}\right)$ in Ref. 5 shows that $\mathrm{F}_{\mathrm{NLC}}$ is highly variable and sensitive to the ratio $\mathrm{R}_{\mathrm{W}}$, the breadth of the input motion frequency content, and the postulated failure mode. Therefore, because of the possible variety of input motions to which the piping component might be subjected, it is impossible to establish any generic relationship between $F_{\mathrm{NLC}}$ and $\mathrm{R}_{\mathrm{W}}$. However, some reasonable but very broad bounds can be established.

The lowest $F_{N L C}$ occur as $R_{W}$ goes to zero for which:

$$
\underline{\text { As } \mathrm{R}_{\underline{W}} \rightarrow 0}: \mathrm{F}_{\mathrm{NLC}} \approx 1.0
$$

However, if low $R_{W}$ values are excluded:

$$
\underline{\mathrm{R}}_{\underline{\mathrm{W}}}>0.7: \mathrm{F}_{\mathrm{NLC}} \approx 2.0 \text { to } 8.0
$$




\section{Estimating Generic ( $\mathrm{F}_{\mathrm{NL}} \underline{\mathrm{F}}_{\mathrm{Red}}$ ) CONS for Piping Systems}

Even at the component test level, the component nonlinear dynamic behavior factor $F_{N L C}$ cannot be established even as a function of $R_{W}$. Only some reasonable but very broad bounds can be established. However, even if $\mathrm{F}_{\mathrm{NLC}}$ could be estimated, this estimate would only establish an unconservative upper bound on $\mathrm{F}_{\mathrm{NL}}$ for a piping system. Many nonlinear dynamic analyses of multidegree-of-freedom systems have demonstrated that the system nonlinear factor $\mathrm{F}_{\mathrm{NL}}$ is generally less than the component factor $F_{\mathrm{NLC}}$, i.e.:

$$
\mathrm{F}_{\mathrm{NL}} \leq \mathrm{F}_{\mathrm{NLC}}
$$

Therefore, in reality one can only realistically estimate $\mathrm{F}_{\mathrm{NL}}$ for a piping system by a nonlinear analysis or a pseudo-linear analysis which approximates the increased effective flexibility of nonlinear components and uses increased effective damping.

However, again some reasonable bounds can be placed on $\mathrm{F}_{\mathrm{NL}}$. So long as the nonlinear behavior is reasonably spread throughout the system:

$$
\begin{aligned}
& \mathrm{F}_{\mathrm{NL}}=\mathrm{F}_{\mathrm{K}}\left(\mathrm{F}_{\mathrm{NLC}}-1.0\right)+1.0 \\
& \mathrm{~F}_{\mathrm{K}} \approx 0.5 \text { to } 0.75
\end{aligned}
$$

In addition, an actual piping system also has a redundancy factor $F_{\text {Red }}$ due to redistribution. Again it would be necessary to perform either a nonlinear or pseudo-linear analysis of the actual piping system to accurately estimate this factor. For a uniform fixed-fixed beam subjected to uniform load, $\mathrm{F}_{\text {Red }}=(16 / 12)=1.33$. In general, for a piping system:

$$
\mathrm{F}_{\mathrm{Red}} \approx 1.0 \text { to } 1.4
$$

Considering the range of parameters defined by Eqns. (14) through (16), for typical piping systems:

$$
\underline{\mathrm{R}}_{\underline{\mathrm{W}} \geq 0.7}\left(\mathrm{~F}_{\mathrm{NL}} \mathrm{F}_{\mathrm{Red}}\right) \approx 1.8 \text { to } 8.3
$$

and even for lower $\mathrm{R}_{\mathrm{W}}$ piping systems, one can generally expect that:

$$
\left(\mathrm{F}_{\mathrm{NL}} \mathrm{F}_{\text {Red }}\right) \geq 1.33
$$


Therefore, a reasonably conservative generic estimate of the product $\left(\mathrm{F}_{\mathrm{NL}} \mathrm{F}_{\mathrm{Red}}\right)$ to cover a wide variety of piping systems and seismic inputs should lie in the range:

$$
\left(\mathrm{F}_{\mathrm{NL}} \mathrm{F}_{\mathrm{Red}}\right)_{\mathrm{CONS} .} \approx 1.33 \text { to } 1.8
$$

and the resulting required $1 \% \mathrm{NEP}$ strength factor $\mathrm{F}_{\mathrm{S}_{1 \%}}$ from Eqn. (4) would be:

\begin{tabular}{|c|c|}
\hline$\left(\mathrm{F}_{\mathrm{NL}} \mathrm{F}_{\text {Red }}\right)_{\text {CONS }}$ & $\mathrm{F}_{\mathrm{S}_{1 \%}}$ \\
\hline 1.33 & 1.5 \\
1.5 & 1.33 \\
1.8 & 1.1 \\
\hline
\end{tabular}

In summary, the ultimate selection of $\left(\mathrm{F}_{\mathrm{NL}} \mathrm{F}_{\mathrm{Red}}\right)_{\mathrm{CONS}}$ and thus the required $\mathrm{F}_{\mathrm{S}_{1 \%}}$ must be by consensus judgment of a committee.

\section{Conclusions}

The ultimate moment $\mathrm{M}_{\mathrm{UD}}$ achieved under dynamic cyclic loading appears to be a stable and predictable parameter which is reliably reached prior to failure irrespective of whether the ultimate failure mode is low cycle fatigue or excessive deformation. Therefore, it is recommended that the Code Moment Capacity $\mathrm{M}_{\mathrm{CODE}}$ be established based upon:

$$
\mathrm{M}_{\mathrm{CODE}}=\frac{\mathrm{M}_{\mathrm{UD}_{1 \%}}}{\mathrm{~F}_{\mathrm{S}}}
$$

where $\mathrm{M}_{\mathrm{UD}_{1 \%}}$ is the $1 \%$ non exceedance probability (NEP) ultimate dynamic moment capacity and $F_{S}$ is an appropriate strength factor of safety.

Based on Eqn. (4) and the information presented in Sections 4 and 5, it is recommended that the strength factor of safety $F_{S}$ lie in the range of 1.1 to 1.5 in order to achieve an overall $1 \% \mathrm{NEP}$ seismic capacity (code) margin $\mathrm{R}_{\mathrm{CP}_{1 \%}}$ of about 2.0. The remainder of this capacity margin is accommodated by nonlinear dynamic behavior and redundancy benefits.

Section 3 shows that Eqn. (5) coupled with either Eqn. (5a) or Eqn. (5b), whichever is appropriate, reliably achieves a strength factor of safety $F_{S}$ of at least 1.5 .

For most actual piping systems the Code Moment Capacity Eqn. (5) combined with either Eqn. (5a) or Eqn. (5b), whichever is appropriate, is expected 
to lead to a Seismic Capacity Margin $\mathrm{R}_{\mathrm{CP}}$ much greater than 2.0. This Seismic Capacity Margin $R_{C P}$ can be estimated from Eqn. (1). As shown in Section 3, the strength factor $\mathrm{F}_{\mathrm{S}}$ is lognormally distributed with a median value $\mathrm{F}_{\mathrm{S}_{50 \%}}=2.2$ and a log. std. sev. $\beta_{\mathrm{S}}$ of 0.16 . The product $\left(\mathrm{F}_{\mathrm{NL}} \mathrm{F}_{\mathrm{Red}}\right)$ is highly variable and cannot reliably be estimated on a generic basis. However as noted in Eqn. (17), my judgment is that for typical piping systems $\left(\mathrm{F}_{\mathrm{NL}} \mathrm{F}_{\mathrm{Red}}\right)$ lies in the range of 1.8 to 8.3. For illustrative purposes, let us assume for a typical piping system and seismic input that the median $\left(\mathrm{F}_{\mathrm{NL}} \mathrm{F}_{\mathrm{Red}}\right)$ is 3.5 with a log. std. def. $\beta_{\mathrm{NLR}}$ of 0.40 . This assumption is equivalent to assuming the $90 \%$ confidence bounds on $\left(\mathrm{F}_{\mathrm{NL}} \mathrm{F}_{\mathrm{Red}}\right)$ are 1.8 to 6.8 . The resulting Seismic Capacity Margin $\mathrm{R}_{\mathrm{CP}}$ has the properties:

$$
\begin{aligned}
\text { Median } \mathrm{R}_{\mathrm{CP}_{50 \%}} & =7.7 \\
\beta_{\mathrm{CP}} & =0.43 \\
1 \% \text { NEP } \mathrm{R}_{\mathrm{CP}_{1 \%}} & =2.8 \\
90 \% \text { Conf. Band } \mathrm{R}_{\mathrm{CP}_{5 \%-95 \%}} & =3.8 \text { to } 15.6
\end{aligned}
$$

In this example, the resulting Seismic Capacity Margin $R_{C P}$ is likely to be exceedingly and unnecessarily high. However, this margin is generically unreliable because $\left(\mathrm{F}_{\mathrm{NL}} \mathrm{F}_{\mathrm{Red}}\right)$ is generically unreliable.

The only way to avoid this problem that the average Seismic Capacity Margins are likely to be exceedingly and unnecessarily high would be to perform either nonlinear or pseudo-linear piping evaluations against a strain or inelastic rotation failure criteria in order to reasonably account for the nonlinear dynamic and redundancy benefits that exist for the specific situation being analyzed. Short of performing such analyses, it is likely to remain necessary to live with the excessive conservatism which will be typically introduced by establishing the Code Moment capacity $\mathrm{M}_{\mathrm{CODE}}$ by Eqn. (5) so as to avoid unconservatism for the odd case where $\left(\mathrm{F}_{\mathrm{NL}} \mathrm{F}_{\mathrm{Red}}\right)$ is low. 


\section{$\underline{\text { References }}$}

1. Kennedy, R.P., "Establishing the Required Seismic Margin for Piping Systems in Nuclear Power Plants," Appendix III-B, NUREG/CR-5361, U.S. Nuclear Regulatory Commission, June 1998

2. Kennedy, R.P., Chokshi, N.C., and Jaquay, K.R., A Technical Basis for Establishing Seismic Margins in Nuclear Plant Piping, Paper K13/3, Transactions of $14^{\text {th }}$ International Conference on Structural Mechanics in Reactor Technology (SMiRT 14), Lyon, France, August 1997.

3. Jaquay, K, Seismic Analysis of Piping, NUREG/CR-5361, U.S. Nuclear Regulatory Commission, June 1998

4. Joint Research Program on Piping Elasto-Plastic Seismic Design Criteria in Japan, Vol. 2-Piping Component Test, December 1998

5. Huang, C.T. and Iwan, W.D., Analytical Study of Frequency Effects on Margins, Appendix II-A, NUREG/CR-5361, U.S. Nuclear Regulatory Commission, June 1998

6. Kennedy, R.P., "Establishing Seismic Design Criteria to Achieve an Acceptable Seismic Margin," Proceedings of the Twenty-fourth Water Reactor Safety Information Meeting, NUREG/CP-0157, Vol. 1, pp. 221224, U.S. NRC, October 1996 


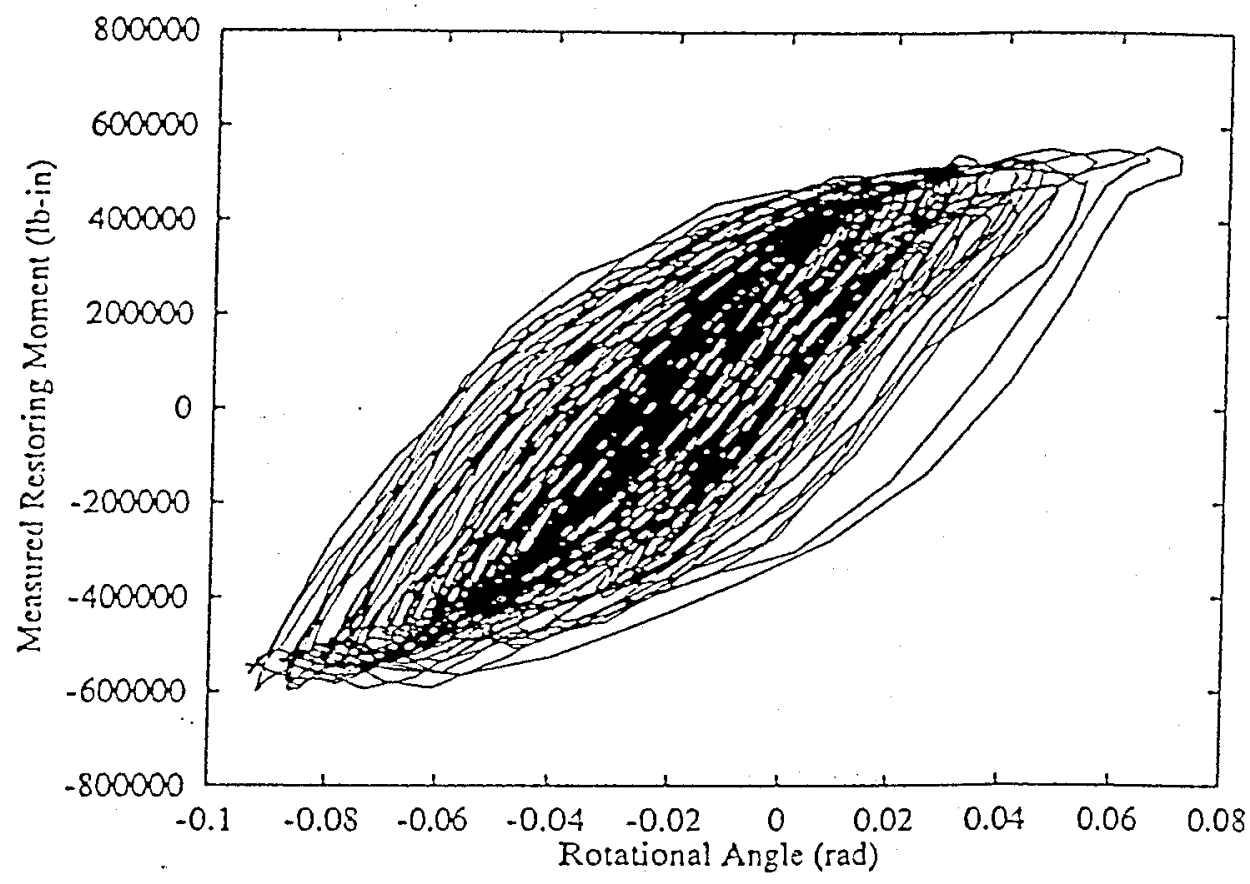

Figure 1: Measured hysteretic loops for ANCO Test 14, Run 6 


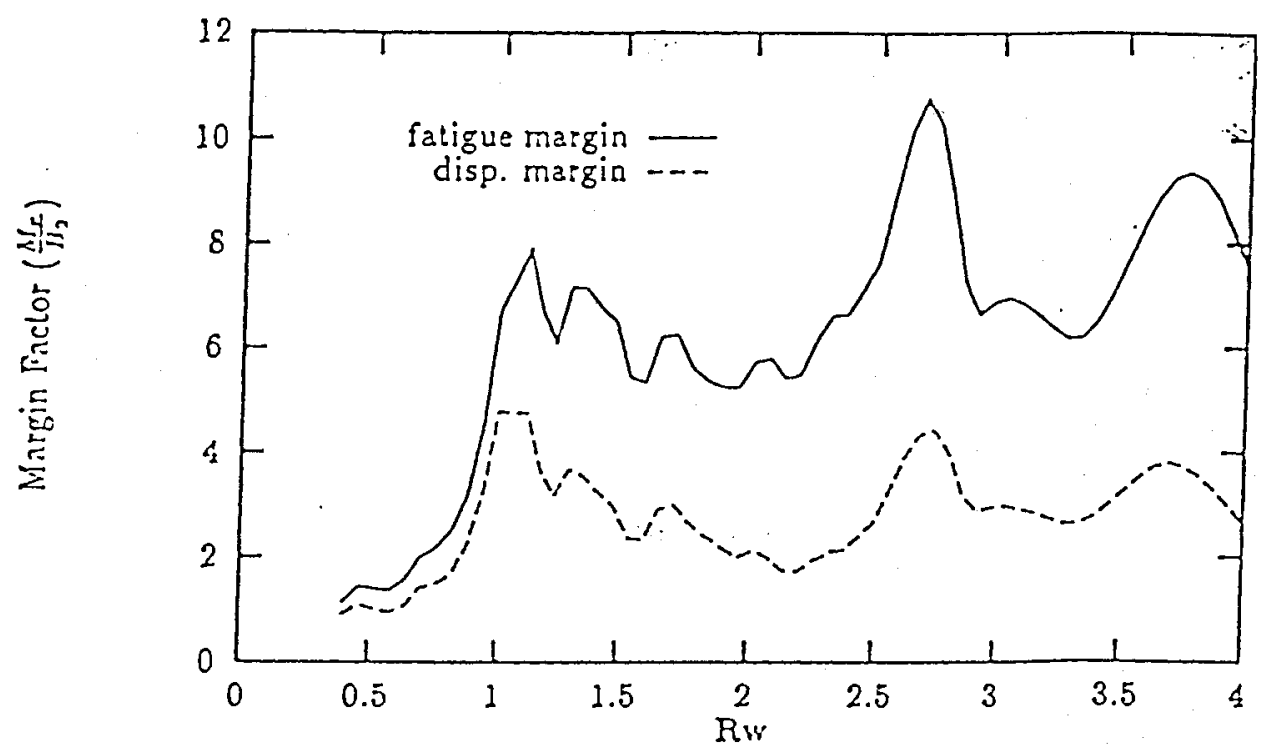

Figure 2: Component 14 Parametric Models, PFDR input; fatigue margin spectrum and displacement margin spectrum, $\alpha w=0 \%, \varsigma^{3}=2.5 \%$ Sequential Method (From Ref. 5.)

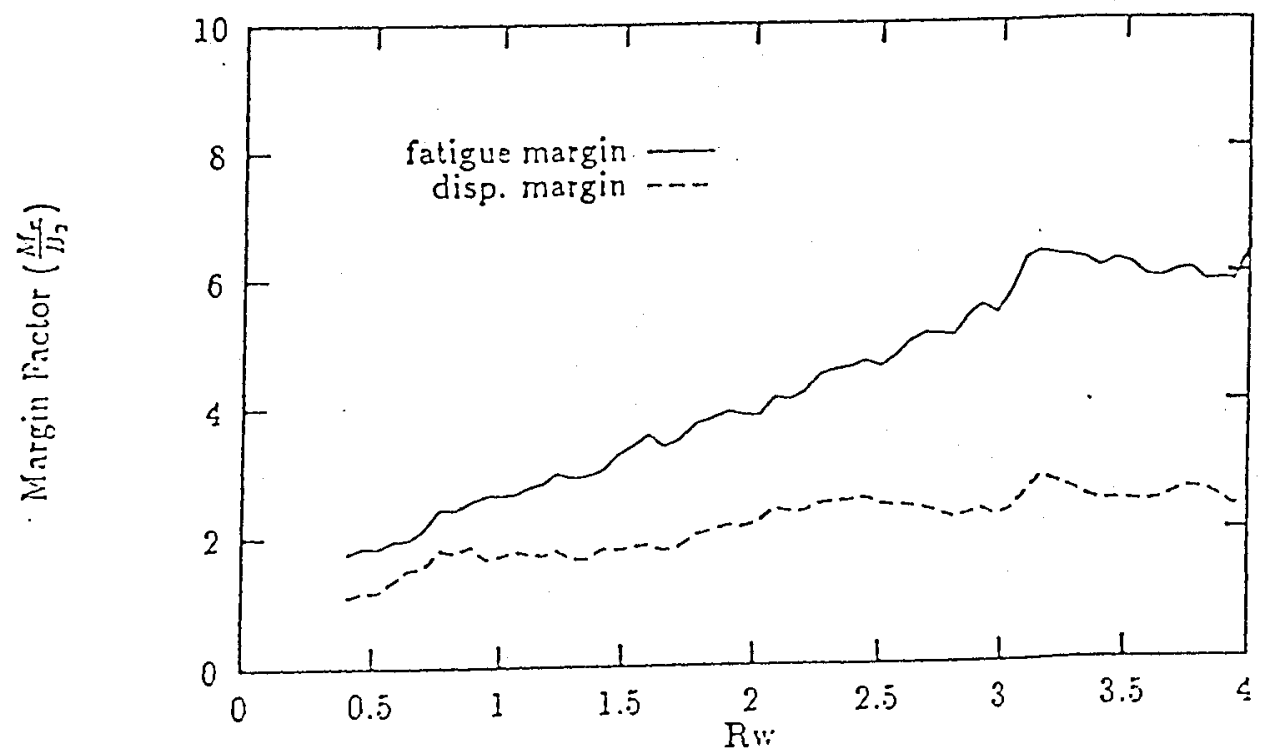

Figure 3: Component 14, Parametric Models, Reg. 1.60 input: fatigue margin spectum and displacement margin spectrum, $\alpha w=0 \%, \varsigma^{3}=2.5 \%$ Sequential Method (From Ref. 5 ) 


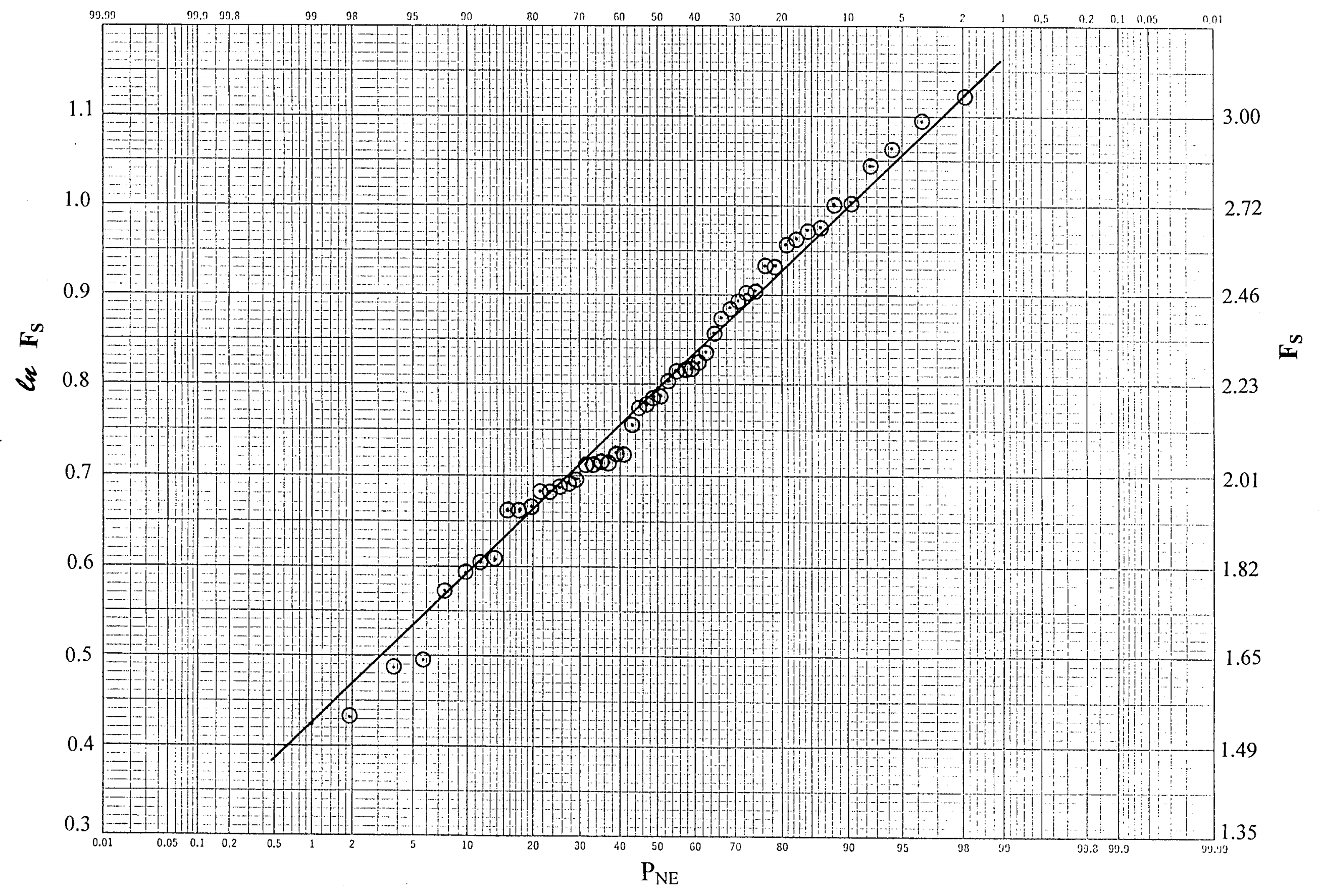

Figure 4: Cumulative Normal Probability $L_{N}$ of Strength Factor 

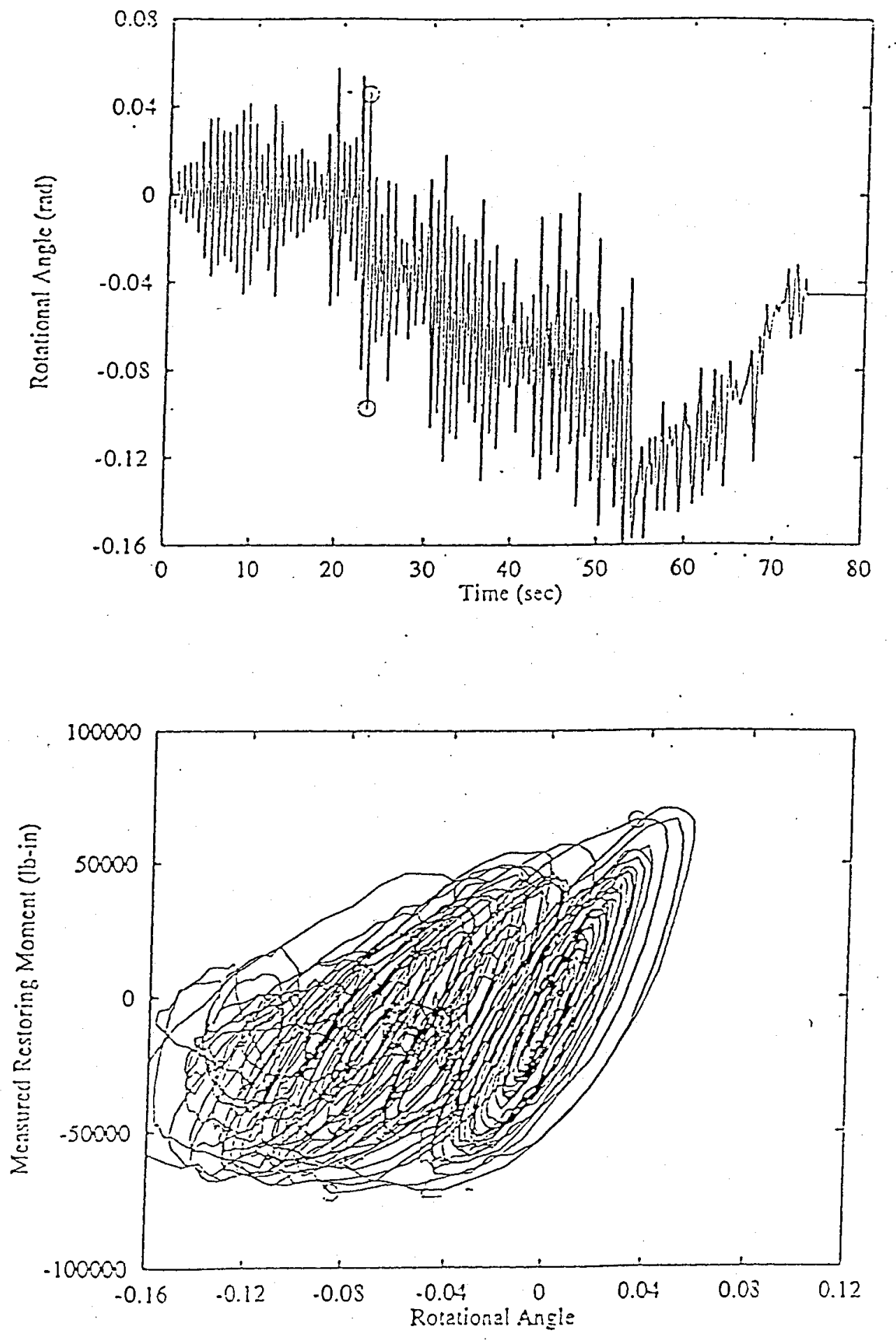

Figure 5: Response time history and hysteretic loops for EPRI Component 37 Run 5 (From Ref. 3) 

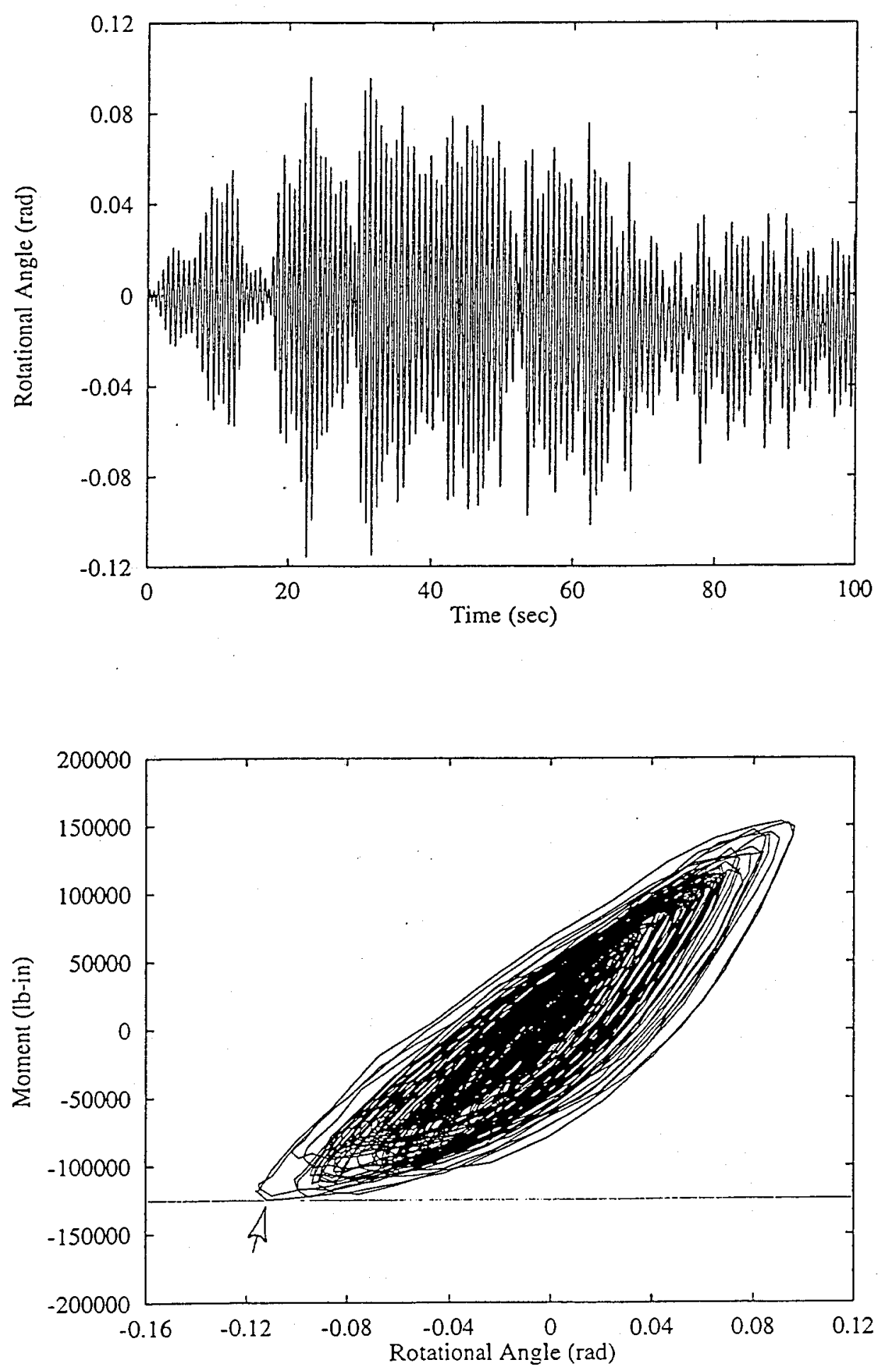

Figure 6: Response time history and hysteretic loops for EPRI Component 30 Run 6 (From Ref. 3) 
Table 1: EPRI Dynamic Component Test Data*

\begin{tabular}{|c|c|c|c|c|c||c||c|c|}
\hline Component & Mtl. & $\begin{array}{c}\mathrm{Z}_{\mathrm{N}} \\
\text { in }^{3}\end{array}$ & $\begin{array}{c}\mathrm{PD}_{0} \\
2 \mathrm{t}\end{array}$ & $\mathrm{B}_{1}$ & $\mathrm{~B}_{2}$ & $\begin{array}{c}\mathrm{M}_{\mathrm{UD}} \\
\text { ksip-inch }\end{array}$ & $\begin{array}{c}\mathrm{M}_{\mathrm{CODE}} \\
\text { kip-inch }\end{array}$ & $\mathrm{F}_{\mathrm{S}}$ \\
\hline Elbow & & & & & & & & \\
3 EL,10,LR & SS & 4.35 & 9.89 & 0 & 5.51 & 142 & 71 & 2.00 \\
4 EL,40,LR & CS & 8.50 & 11.83 & 0 & 3.27 & 381 & 234 & 1.63 \\
5 EL,40,LR & CS & 8.50 & 20.11 & 0 & 3.27 & 478 & 234 & 2.05 \\
6 EL,40,LR & SS & 8.50 & 20.11 & 0 & 3.27 & 469 & 234 & 2.01 \\
7 EL,40,LR & SS & 8.50 & 11.83 & 0 & 3.27 & 454 & 234 & 1.94 \\
8 EL,40,LR & SS & 8.50 & 0 & 0 & 3.27 & 456 & 234 & 1.95 \\
13 EL,40,SR & CS & 8.50 & 11.83 & 0 & 4.29 & 322 & 178 & 1.81 \\
19 EL,40,SR & SS & 8.50 & 29.58 & 0 & 3.27 & 579 & 234 & 2.47 \\
30 EL,10,LR & SS & 4.35 & 9.89 & 0 & 5.51 & 130 & 71 & 1.83 \\
31 EL,10,LR & SS & 4.35 & 9.89 & 0 & 5.51 & 188 & 71 & 2.65 \\
35 EL,40,LR & CS & 8.50 & 20.11 & 0 & 3.27 & 465 & 234 & 1.99 \\
37 EL,10,LR & SS & 4.35 & 0 & 0 & 5.51 & 70 & 71 & $0.99 * *$ \\
41 EL,40,LR & CS & 8.50 & 20.11 & 0 & 3.27 & 499 & 234 & 2.13 \\
\hline Non Elbow & & & & & & & & \\
9 Tee, 40 & SS & 8.50 & 20.11 & 0.5 & 1.0 & 629 & 318 & 1.98 \\
10 Tee, 40 & SS & 8.50 & 11.83 & 0.5 & 1.0 & 635 & 345 & 1.84 \\
11 Tee, 10 & SS & 4.35 & 9.89 & 0.5 & 1.0 & 369 & 180 & 2.05 \\
12 Tee, 40 & SS & 8.50 & 20.11 & 0.5 & 1.0 & 719 & 318 & 2.26 \\
14 Tee, 40 & CS & 8.50 & 20.11 & 0.5 & 1.0 & 617 & 318 & 1.94 \\
15 Red, 40 & SS & 3.21 & 16.14 & 0.5 & 1.0 & 333 & 125 & 2.66 \\
16 Red, 40 & CS & 3.21 & 16.14 & 0.5 & 1.0 & 385 & 125 & 3.08 \\
34 Pipe, 40 & CS & 8.50 & 11.83 & 0.5 & 1.0 & 759 & 345 & 2.20 \\
36 Tee, 40 & CS & 8.50 & 20.11 & 0.5 & 1.0 & 700 & 318 & 2.20 \\
38 Tee, 40 & SS & 8.50 & 20.11 & 0.5 & 2.02 & 643 & 315 & 2.04 \\
39 Tee, 40 & SS & 8.50 & 0 & 0.5 & 2.02 & 623 & 379 & 1.64 \\
40 Red, 40 & SS & 3.21 & 0 & 0.5 & 1.0 & 314 & 144 & 2.17 \\
\hline
\end{tabular}

$* \mathrm{~S}_{\mathrm{M}}=20 \mathrm{ksi}$ all cases

**Component 37 is an outlier not included in statistical comparison 
Table 2: Japanese Dynamic Component Test Data

\begin{tabular}{|c|c|c|c|c|c|c|c|c|c|}
\hline Component & $\overline{\text { Mtl. }}$ & $\begin{array}{c}\mathrm{S}_{\mathrm{M}} \\
\mathrm{N} / \mathrm{mm}^{2}\end{array}$ & $\begin{array}{c}\mathrm{Z}_{\mathrm{N}} \\
\mathrm{mm}^{3}\end{array}$ & $\begin{array}{l}\frac{\mathrm{PD}_{0}}{2 \mathrm{t}} \\
\mathrm{MP}_{\mathrm{a}}\end{array}$ & $\overline{\mathrm{B}_{1}}$ & $\overline{B_{2}}$ & $\begin{array}{l}\mathrm{M}_{\mathrm{UD}} \\
\mathrm{kNm}\end{array}$ & $\begin{array}{c}\mathrm{M}_{\mathrm{CODE}} \\
\mathrm{kNm}\end{array}$ & $\overline{F_{S}}$ \\
\hline \multicolumn{10}{|l|}{ Bends } \\
\hline 1 & CS & 110.3 & 52530 & 126.7 & 0 & 2.16 & 31.80 & 12.07 & 2.63 \\
\hline 2 & SS & 137.9 & 52530 & 142.9 & 0 & 2.16 & 45.20 & 15.09 & 3.00 \\
\hline 3 & $\mathrm{CS}$ & 110.3 & 96712 & 69.0 & 0 & 1.14 & 58.28 & 24.00 & 2.43 \\
\hline 4 & $\mathrm{CS}$ & 110.3 & 52530 & 70.5 & 0 & 2.16 & 29.50 & 12.07 & 2.44 \\
\hline 5 & $\mathrm{CS}$ & 110.3 & 52530 & 17.1 & 0 & 2.16 & 25.00 & 12.07 & 2.07 \\
\hline 7 & CS & 110.3 & 52530 & 125.7 & 0 & 2.16 & 21.31 & 12.07 & 1.77 \\
\hline 8 & $\mathrm{CS}$ & 110.3 & 52530 & 127.6 & 0 & 2.16 & 26.35 & 12.07 & 2.18 \\
\hline 10 & $\mathrm{CS}$ & 110.3 & 52530 & 129.5 & 0 & 2.16 & 34.40 & 12.07 & 2.85 \\
\hline \multicolumn{10}{|l|}{ Tees } \\
\hline 11 & $\mathrm{CS}$ & 110.3 & 55243 & 125.7 & 0.5 & 2.17 & 24.17 & 10.24 & 2.36 \\
\hline 12 & CS & 110.3 & 20635 & 95.4 & 0.5 & 1.0 & 10.00 & 4.38 & 2.28 \\
\hline 13 & CS & 110.3 & 55243 & 130.5 & 0.5 & 1.0 & 21.79 & 11.01 & 1.98 \\
\hline \multicolumn{10}{|l|}{ Pipe } \\
\hline 14 & $\mathrm{CS}$ & 110.3 & 52530 & 122.9 & 0.5 & 1.0 & 23.65 & 10.62 & 2.23 \\
\hline 15 & $\mathrm{CS}$ & 110.3 & 52530 & 135.3 & 0.5 & 1.0 & 21.21 & 10.37 & 2.04 \\
\hline
\end{tabular}


Table 3: Japanese Cyclic Static Component Test Data

\begin{tabular}{|c|c|c|c|c|c|c|c||c|c|}
\hline Component & Mtl. & $\begin{array}{c}\mathrm{S}_{\mathrm{M}} \\
\mathrm{N} / \mathrm{mm}^{2}\end{array}$ & $\begin{array}{c}\mathrm{Z}_{\mathrm{N}^{3}} \\
\mathrm{~mm}^{3}\end{array}$ & $\begin{array}{c}\frac{\mathrm{PD}_{0}}{2 \mathrm{t}} \\
\mathrm{MP}_{\mathrm{a}}\end{array}$ & $\mathrm{B}_{1}$ & $\mathrm{~B}_{2}$ & $\begin{array}{c}\mathrm{M}_{\mathrm{UD}} \\
\mathrm{kNm}\end{array}$ & $\begin{array}{c}\mathrm{M}_{\mathrm{CODE}} \\
\mathrm{kNm}\end{array}$ & $\mathrm{F}_{\mathrm{S}}$ \\
\hline Bends & & & & & & & & & \\
$\mathbf{1}$ & $\mathrm{CS}$ & 110.3 & 52530 & 126.7 & 0 & 2.16 & 32.86 & 12.07 & 2.72 \\
$\mathbf{2}$ & $\mathrm{SS}$ & 137.9 & 52530 & 136.2 & 0 & 2.16 & 34.28 & 15.09 & 2.27 \\
$\mathbf{3}$ & $\mathrm{CS}$ & 110.3 & 96712 & 66.5 & 0 & 1.14 & 69.36 & 24.00 & 2.89 \\
$\mathbf{4}$ & $\mathrm{CS}$ & 110.3 & 52530 & 61.0 & 0 & 2.16 & 27.84 & 12.07 & 2.31 \\
$\mathbf{5}$ & $\mathrm{CS}$ & 110.3 & 52530 & 3.8 & 0 & 2.16 & 24.99 & 12.07 & 2.07 \\
$\mathbf{7}$ & $\mathrm{CS}$ & 110.3 & 52530 & 124.8 & 0 & 2.16 & 18.64 & 12.07 & 1.54 \\
$\mathbf{8}$ & $\mathrm{CS}$ & 110.3 & 52530 & 127.6 & 0 & 2.16 & 28.95 & 12.07 & 2.40 \\
$\mathbf{9}$ & $\mathrm{CS}$ & 110.3 & 52530 & 127.6 & 0 & 2.16 & 32.82 & 12.07 & 2.73 \\
$\mathbf{1 1}$ & $\mathrm{CS}$ & 110.3 & 52530 & 125.7 & 0 & 2.16 & 30.61 & 12.07 & 2.54 \\
\hline $\mathbf{T e e s}$ & & & & & & & & & \\
\hline $\mathbf{1 2}$ & $\mathrm{CS}$ & 110.3 & 55243 & 125.7 & 0.5 & 2.17 & 25.95 & 10.24 & 2.54 \\
$\mathbf{1 3}$ & $\mathrm{CS}$ & 110.3 & 20635 & 95.4 & 0.5 & 1.0 & 11.43 & 4.38 & 2.61 \\
$\mathbf{1 4}$ & $\mathrm{CS}$ & 110.3 & 55243 & 123.8 & 0.5 & 1.0 & 27.38 & 11.15 & 2.46 \\
\hline Pipe & & & & & & & & & \\
\hline $\mathbf{1 5}$ & $\mathrm{CS}$ & 110.3 & 52530 & 123.8 & 0.5 & 1.0 & 23.90 & 10.60 & 2.26 \\
\hline
\end{tabular}


Table 4: Comparison of Statistical Distribution for EPRI and Japanese Test Data

\begin{tabular}{|c|c|c|c|c|}
\hline & EPRI & \multicolumn{2}{|c|}{ Japanese } & \multirow{2}{*}{ Combined } \\
\cline { 3 - 4 } & Dynamic & Dynamic & Cyclic Static & \\
\hline Number of Tests & 24 & 13 & 13 & 50 \\
\hline $\mathrm{F}_{\mathrm{S}_{50 \%}}$ & 2.08 & 2.30 & 2.38 & 2.21 \\
$\beta_{\mathrm{S}}$ & 0.15 & 0.15 & 0.16 & 0.16 \\
$\mathrm{~F}_{\mathrm{S}_{1 \%}}$ & 1.47 & 1.63 & 1.64 & 1.53 \\
\hline
\end{tabular}

Table 5: Comparison of Statistical Distributions for Fitting Body Failures Versus Near Weld Failures

\begin{tabular}{|c|c|c|c|}
\hline & $\begin{array}{c}\text { Fitting Body } \\
\text { (Eqn. 5a) }\end{array}$ & $\begin{array}{c}\text { Near Weld } \\
\text { (Eqn. 5b) }\end{array}$ & Combined \\
\hline Number of Tests & 33 & 17 & 50 \\
\hline $\mathrm{F}_{\mathrm{S}_{50 \%}}$ & 2.21 & 2.23 & 2.21 \\
$\beta_{\mathrm{S}}$ & 0.18 & 0.13 & 0.16 \\
$\mathrm{~F}_{\mathrm{S}_{1 \%}}$ & 1.47 & 1.65 & 1.53 \\
\hline
\end{tabular}

Table 6: Comparison of Statistical Distribution for Carbon Steel Versus Stainless Steel Components

\begin{tabular}{|c|c|c|c|}
\hline & $\begin{array}{c}\text { Carbon Steel } \\
\text { CS }\end{array}$ & $\begin{array}{c}\text { Stainless Steel } \\
\text { SS }\end{array}$ & Combined \\
\hline Number of Tests & 33 & 17 & 50 \\
\hline $\mathrm{F}_{\mathrm{S}_{50 \%}}$ & 2.26 & 2.14 & 2.21 \\
$\beta_{\mathrm{S}}$ & 0.16 & 0.16 & 0.16 \\
$\mathrm{~F}_{\mathrm{S}_{1 \%}}$ & 1.55 & 1.49 & 1.53 \\
\hline
\end{tabular}

